\title{
A PERCEPÇÃO DOS DOCENTES QUANTO ÀS PRÁTICAS DE CONTABILIDADE ESTRATÉGICA: UM ESTUDO COMPARATIVO
}

\author{
THE PROFESSORS’ PERCEPTION REGARDING STRATEGIC \\ ACCOUNTING PRACTICES: A COMPARATIVE STUDY
}

\author{
PAULA DANYELLE ALMEIDA DA SILVA \\ Mestre em Ciências Contábeis \\ pela Faculdade de Administração e Ciências Contábeis \\ da Universidade Federal do Rio de Janeiro - RJ \\ E-mail: pauladanyelle@terra.com.br
}

\author{
ODILANEI MORAIS DOS SANTOS \\ Mestre em Ciências Contábeis \\ pela Faculdade de Administração e Ciências Contábeis \\ da Universidade Federal do Rio de Janeiro - RJ \\ E-mail: odilaneisantos@terra.com.br
}

\author{
ARACÉLI CRISTINA DE SOUSA FERREIRA \\ Professora Titular \\ da Faculdade de Administração e Ciências Contábeis \\ da Universidade Federal do Rio de Janeiro - RJ \\ E-mail: araceli@ufr.br
}

\section{RESUMO}

O objetivo deste estudo é medir o grau de compreensão e uso do termo "Contabilidade Estratégica" e o mérito de determinadas práticas consideradas de Contabilidade Estratégica, de acordo com a percepção dos docentes de programas de pós-graduação stricto sensu em Contabilidade no Brasil. Adicionalmente, os resultados obtidos são comparados com pesquisas realizadas com controllers em nível nacional e internacional. Trata-se de um estudo descritivo, delineado por meio da utilização de questionário com questões fechadas e pontuadas em escala Likert. A amostra contou com a participação de 43 respondentes, de um universo de 104 professores ministrantes de disciplina de Contabilidade e representantes dos programas de pós-graduação stricto sensu em Ciências Contábeis. A margem de erro é de $10 \%$, para um nível de confiança de $90 \%$. Na escala de variação de 1 a 7 , a média para o nível de percepção dos docentes quanto à compreensão do termo "Contabilidade Estratégica" ficou em 5,14, aliado a um uso menos intenso, com média de 4,02. Esses resultados sugerem que a temática ainda não é totalmente pacífica, podendo-se dizer que se trata de uma abordagem emergente na Contabilidade. Em relação às práticas de Contabilidade Estratégica, os resultados apontam como medidas que podem levar as empresas a obter e manter vantagens competitivas. No estudo comparativo, as médias obtidas no estudo com os docentes foram maiores do que os estudos realizados com os controllers no Brasil e em nível internacional, mostrando, intuitivamente, que os docentes teriam uma melhor compreensão do tema do que os controllers. Entretanto, testes não-paramétricos indicaram não haver diferenças estatísticas significativas entre as médias obtidas.

Palavras-chave: Contabilidade Estratégica; Vantagem Competitiva; Docentes de Contabilidade.

\section{ABSTRACT}

This study aims to gauge the degree of utilization and understanding of the expression "Strategic Accounting", as well as the merit of some practices regarded as being of strategic accounting, in accordance with lecturers' perception of Brazilian Stricto Sensu post graduation programs in Accounting. Furthermore, the outcomes will be compared with researches made with controllers, both domestic and foreign. It is a descriptive study, outlined through the use of closed questions, punctuated in Likert scale. The sample took into consideration 43 out of 104 Accounting professors and representatives of Stricto Sensu post graduation programs. in Accounting. The error margin is of $10 \%$ for a confidence level of $90 \%$. In a scale ranging from 1 to 7 , the average attained for the academicians' perception regarding the understanding of the expression "strategic accounting" was 5,14, in addition to a less intense use, with an average of 4,02. These outcomes suggest that the issue is not totally accepted, without raising oppositions or discussions of some kind, what leads to believing that it deals with an emergent approach in accountancy. In relation to the practices of strategic accounting, the results point to measurements that can lead corporations to attain and maintain competitive advantages. In the comparative study, the averages achieved with academicians were. higher than the averages achieved with the Brazilian controllers, both domestic and worldwide, showing, intuitively, that the academic would have a better understanding of the issue than the controllers. However, non-parametric tests indicate that there are not any relevant statistical differences among the grades achieved.

Keywords: Strategic Accounting; Competitive Advantage; Accounting Academicians. 


\section{INTRODUÇÃO}

Desde sua sistematização a Contabilidade busca atender às necessidades cada vez mais complexas e diferenciadas de seus inúmeros usuários, os quais, invariavelmente, apresentam objetivos distintos. A Contabilidade Comercial, a Contabilidade Financeira, a Contabilidade de Custos e a Contabilidade Gerencial são exemplos dessa evolução e respostas da ciência contábil às necessidades informacionais de seus usuários.

O dinamismo do mundo dos negócios faz com que a Ciência Contábil se depare com novas demandas, onde não é suficiente apenas o registro e divulgação dos fatos já acontecidos. A visão contábil deve ser ampliada, indo além das informações produzidas pelos fatos já conhecidos para as atividades de planejamento, de modo a antever as conseqüências para a empresa no futuro e tornando-se parte integrante do processo de decisão da empresa.

Nesse contexto, surge o enfoque de Contabilidade Estratégica, que visa prover e analisar os dados contábeis que dizem respeito à estratégia da empresa, de modo a prever mudanças nos cenários futuros e assinalar a necessidade de mudanças nas estratégias da empresa. (GOLDENBERG, 1994).

Com isso, a Contabilidade Estratégica estaria mais voltada ao ambiente externo, como, por exemplo, a avaliação de informações sobre a concorrência, os fornecedores, os clientes e, até mesmo, aos consumidores, atuando juntamente com as demais áreas da empresa na elaboração de planos de longo prazo, estimando comparativamente o valor da vantagem competitiva da empresa ou o valor adicionado sobre seus competidores e avaliando o rendimento de seus produtos.

Contudo, conforme argumento de Coad (1996), esse ramo da Contabilidade ainda não tem seus limites perfeitamente delineados, tratando-se de um campo emergente, no qual não se tem uma visão unificada do que vem ser Contabilidade Estratégica e como ela pode se desenvolver, como pode ser percebida pela literatura discordante e desarticulada existente sobre o tema.

A motivação principal para este estudo surgiu de um levantamento das pesquisas publicadas sobre o tema Contabilidade Estratégica nos Anais dos congressos brasileiros e periódicos, classificados como nível $A$ e $B$, no período de 2000 a 2005, cujo objetivo foi identificar o estado da arte no Brasil sobre o tema e delinear um quadro de referência sobre planejamento e estratégia que pudesse ser aplicado à área contábil nos seus aspectos acadêmico e operacional.

Do quadro de referências levantado, destacou-se o trabalho desenvolvido por Grzeszezeszyn e Ferreira (2004), que aborda questões relacionadas ao nível de compreensão, uso e mérito de algumas práticas de Contabilidade Estratégica e, ainda, compara seus resultados com os obtidos por Guilding, Cravens e Tayles (2000) em pesquisa semelhante.

Tanto a pesquisa realizada por Guilding, Cravens e Tayles (op. cit.) quanto a de Grzeszezeszyn e Ferreira (op. cit.) tiveram como objetivo: a) medir o uso e o mérito de determinadas práticas de Contabilidade Estratégica e b) medir a compreensão e o uso do termo "Contabilidade Estratégica" ou "Contabilidade Gerencial Estratégica", segundo a percepção de profissionais (controllers) de grandes empresas.

A pesquisa de Guilding, Cravens e Tayles foi realizada com controllers de grandes empresas situadas no Reino Unido, Estados Unidos e Nova Zelândia e contou com uma amostra de 297 componentes.

Grzeszezeszyn e Ferreira, por sua vez, pesquisaram a percepção dos controllers de grandes empresas brasileiras situadas nas Regiões Sul e Sudeste do Brasil e contou com uma amostra de 19 componentes.

De modo geral, as duas pesquisas indicavam níveis maiores de concordância quando se referiam ao mérito das práticas de Contabilidade Estratégica, ou mesmo quanto à compreensão do termo "Contabilidade Estratégica", do que quando se tratava da questão do uso efetivo de tais práticas ou do termo, sugerindo haver espaço para o aperfeiçoamento dos conhecimentos relacionados à Contabilidade Estratégica para permitir um maior uso de suas práticas.

Com a premissa de ser a academia um celeiro de concepção e desenvolvimento de idéias, conceitos e práticas de gestão empresarial, é intuitivo imaginar que seus docentes e pesquisadores apresentem elevados níveis de compreensão sobre essas práticas de gestão e atribuam, da mesma forma, alto nível de importância quanto ao mérito delas.

Em relação à Contabilidade Estratégica, Dixon (1998, p. 279) reforça essa intuição ao afirmar que:

O conceito de Contabilidade Estratégica tem que ser desenvolvido por profissionais e acadêmicos, mas para isso deve haver maior interação entre os dois. Este conceito pode ser desenvolvido além do seu estado atual e alcançar aplicação mais difundida de modo a ajudar as organizações a aumentarem suas vantagens competitivas num mercado intensamente competitivo

Tendo por base essa percepção e as conclusões das pesquisas de Guilding, Cravens e Tayles (2000) e Grzeszezeszyn e Ferreira (2004), desenvolveu-se este estudo com docentes de programas de pós-graduação stricto sensu em Ciências Contábeis do Brasil, com o objetivo de:

(a) medir o grau de compreensão do significado de "Contabilidade Estratégica";

(b) constatar se o termo "Contabilidade Estratégica" é usado nas atividades profissionais dos pesquisados;

(c) medir a relevância (mérito) de determinadas práticas de Contabilidade Estratégica para as empresas e

(d) comparar os resultados obtidos com aqueles apontados por Guilding, Cravens e Tayles (2000) e Grzeszezeszyn e Ferreira (2004). 


\section{REFERENCIAL TEÓRICO}

A Contabilidade é utilizada pelas organizações como instrumento informacional, estando intrinsecamente relacionada às necessidades de seus usuários. Desse modo, a missão de prover informações úteis evoluiu juntamente com a complexidade das empresas e das organizações que utilizam o sistema contábil.

A Contabilidade solidificou não só sua sistematização prática mas também as teorias que sustentam seu arcabouço conceitual. Essa separação é percebida quando ocorre a dissociação entre seus aspectos práticos e seu fundamento científico.

Desde sua sistematização, a Contabilidade busca atender necessidades cada vez mais complexas e diferenciadas de seus inúmeros usuários, que invariavelmente apresentam objetivos distintos. Segundo Ferreira, Portugal e Nigri (2001), "a informação contábil teria um desenvolvimento não linear, quando se tomam os usuários e seus interesses", ou seja, adequando-se às necessidades de seus diversos usuários.

A característica de modelar-se conforme as expectativas dos usuários demonstra a flexibilidade da informação contábil. Nesse aspecto, Ferreira, Portugal e Nigri (2001) afirmam que fatores como necessidades de longo prazo ou curto prazo; perspectiva do acionista ou do gerente e enfoque operacional ou financeiro representam alguns dos muitos fatores imprescindíveis quando se aborda uma questão contábil.

Entretanto, essa flexibilidade também pode representar a fragilidade da informação, pois a multiplicidade de interesses poderá ocasionar a perda de foco e conseqüentemente a perda do seu objetivo principal (fornecimento de informações úteis). Os autores ponderam ainda que por esse motivo o atendimento satisfatório de todos os usuários, através de um sistema de contabilidade único, não é possível nem plausível.

Assim, é necessária a segregação da Contabilidade em ramos que busquem atender de forma mais adequada às necessidades de seus usuários e, assim, auxiliá-los na obtenção de informações úteis no gerenciamento das organizações e interesses. Considerando a divisão clássica temse: Contabilidade Financeira e Contabilidade Gerencial.

$\mathrm{Na}$ Contabilidade Financeira, os objetivos e fundamentos estão relacionados com um grupo específico de usuário: os usuários externos. De acordo com Hendriksen e Van Breda (1999), para a formação do referencial teórico da Contabilidade Financeira, instituíram-se princípios e padrões de modo a garantir a produção de informações confiáveis a esses usuários externos. Dessa forma, a Contabilidade Financeira está direcionada aos usuários externos, em que as informações visam informar a evolução patrimonial da entidade a partir de padrões e princípios pré-estabelecidos.

A Contabilidade Gerencial está direcionada ao processo interno da informação contábil, auxiliando os gestores no processo de tomada de decisão. De acordo com Lopes e Martins (2005, p. 95), a Contabilidade Gerencial desen- volveu seu arcabouço nas décadas de 60 e 70 a partir do estudo da estrutura de custos das empresas. Esse modelo ainda continua sendo usado, entretanto, sua adaptação ao atual contexto econômico é requisito fundamental. Ainda de acordo com os autores (op. cit., p.96):

a desconsideração de questões tão relevantes da realidade empresarial ocasionou uma certa descrença na capacidade da Contabilidade Gerencial de fornecer informações realmente úteis para a gestão das firmas.

De forma mais específica, Stainer (1997, p. 57) afirma que

o foco da Contabilidade Gerencial tradicional nos custos internos deve ser ampliado para abraçar (envolver) fatores externos

De acordo com Nossa e Holanda (1998), muitas das informações relevantes dos custos dos produtos ou serviços, e os lucros deles derivados, estão tradicionalmente na área da Contabilidade Gerencial. Apesar de a Contabilidade possuir em sua estrutura os fundamentos necessários para vir a ser o sistema de informação mais importante da empresa, transformando-se no centro de integração e interação com os seus demais sistemas, isso não acontece.

O sistema contábil gerencial tradicional traz inquestionáveis benefícios, porém não evidencia os tópicos que as organizações encaram quando estão tentando desenvolver uma estratégia competitiva. (NOSSA e HOLANDA, 1998).

Ainda nesse contexto, Johnson e Kaplan (1993, p. 65) reforçam essa idéia:

Os sistemas de Contabilidade Gerencial das empresas são inadequados para a realidade atual. Nesta era de rápida mudança tecnológica, de vigorosa competição global e doméstica e uma enorme expansão da capacidade de processamento das informações, os sistemas de Contabilidade Gerencial estão deixando de fornecer informações úteis, oportunas para as atividades de controle de processos, avaliação de custos dos produtos e avaliação de desempenho dos gerentes.

Nesse cenário, surgiram teorias que mudaram a abordagem da Contabilidade Gerencial, como, por exemplo: pesquisa comportamental; teoria das organizações; teoria social e pesquisas voltadas à prática. Além dessas teorias, na busca da reformulação da Contabilidade Gerencial surge a abordagem da Contabilidade Estratégica.

Grzeszezeszyn e Ferreira (2004) descrevem o histórico do termo Contabilidade Gerencial Estratégica afirmando que a primeira menção do termo em pesquisa científica foi feita por Simmonds (1981), o qual a definiu como:

provisão e análise de dados da Contabilidade Gerencial sobre um negócio e seus competidores para uso 
no desenvolvimento e monitoramento da estratégia empresarial.

Nessa linha de pensamento, Shank e Govindarajan (1997, p. 5) afirmam que "a Contabilidade existe na administração principalmente para facilitar o desenvolvimento e a implementação da estratégia empresarial”, ou seja, ela deve participar do processo estratégico cíclico, que consiste em formular estratégias; comunicar essas estratégias a toda a organização; desenvolver e pôr em prática as táticas para implementar as estratégias e desenvolver e implementar controles para monitorar as etapas de implementação da estratégia e depois o sucesso no alcance das metas estratégicas.

Para Goldenberg (1994), a Contabilidade Estratégica é um ramo da Contabilidade que está em crescimento e ela a considera importante pois procura estimar comparativamente o valor da vantagem competitiva da empresa ou o valor adicionado sobre seus competidores e avaliar os benefícios do rendimento dos produtos em relação ao curso de vida dos clientes e os benefícios que esses rendimentos gerarão para a empresa sobre uma decisão de longo prazo.

Dixon (1998, p. 272) afirma que a Contabilidade Estratégica deve:

procurar identificar as estratégias que criam van-

tagem competitiva e clarificam o plano estratégico da empresa.

Ferreira, já em 1992, alertava para a necessidade de o contador ampliar seus horizontes, desempenhando um papel estratégico nas organizações. Para tanto, seria necessário, além do conhecimento interno da própria empresa, ter uma visão ampla do ambiente externo, de forma que as informações referentes aos concorrentes, fornecedores, clientes, dentre outros, pudessem se traduzir em vantagens competitivas ao adicionar valor ao negócio.

Nossa e Holanda (1998), também, apresentam argumentação semelhante. Segundo os autores, o potencial da Contabilidade para gerar informações Estratégicas é significativo e a necessidade de gerenciamento contábil estratégico é, sem dúvida, um dos maiores desafios para as empresas do futuro. Com isso, é preciso uma atitude proativa por parte dos contadores. É necessário voltar-se para as finalidades dos sistemas que em última análise devem expressar os anseios dos usuários.

Para Dixon (1998, p. 273):

o conceito de Contabilidade Gerencial Estratégica exige dos contadores gerenciais focarem na mensuração da performance em vez de indicadores táticos.

Simmonds (1981) afirma que:

a habilidade do contador deveria ser usada junto com a análise de informações internas e com a apresentação de dados pertinentes aos competidores.

ludícibus (1994) apresenta uma indagação interessante sobre a temática, qual seja: será o sistema contábil geren- cial em si que deve assumir uma dimensão estratégica, perfeitamente definida ou será o profissional, o controller, que pode materializar, pelo seu trabalho, essa função estratégica? O autor conclui que as duas vertentes estão corretas, embora a primeira ainda esteja em seus estágios iniciais e a segunda - o profissional estrategista - deva ser uma necessidade constante.

A grande dificuldade para o desenvolvimento da Contabilidade Estratégica apontada por ludícibus (1994) reside no fato de que usualmente os sistemas de informações contábeis e gerenciais são delineados tendo em vista o nível operacional e tático da organização e que é difícil para os sistemas gerenciais incluírem o estratégico, pois os resultados e objetivos a serem alcançados, e que fazem parte do planejamento estratégico, não são facilmente mensuráveis em unidades monetárias, pelo menos de forma mais detalhada, expressando-se melhor em unidades físicas e qualitativas.

De acordo com ludícibus, Martins e Carvalho (2005, p. 13), a morfologia contábil estabelece as medidas e classificações das espécies e subespécies da Contabilidade, sendo importante no seu processo evolutivo das espécies contábeis, nas quais em cada subespécie, existem classificações específicas, bem como medidas e indicadores especiais que se atêm às características da subespécie. É o que ocorre com a Contabilidade Estratégica.

Cotejando os vários aspectos apresentados pela literatura, entende-se que a Contabilidade Estratégica não é um ramo autônomo que está sendo criado ou defendido, mas uma subespécie da Contabilidade Gerencial, configurandose como um ramo cuja especialidade seria coletar e interpretar dados extraídos do ambiente externo, ou seja, dos concorrentes, fornecedores, clientes, potenciais consumidores, para que sejam geradas informações que suportem de fato as decisões estratégicas da empresa, cabendo ao contador possuir habilidades para desempenhar um papel estratégico na organização com vistas à criação de vantagens competitivas que agreguem valor ao negócio.

Para que tudo isso seja posto em prática é necessário o desempenho de certas práticas de Contabilidade Estratégica. Conforme apontam Grzeszezeszyn e Ferreira (2004), essas práticas são inúmeras e variadas, passando por aquelas que relacionam a Contabilidade Gerencial e os investimentos da empresa ou ainda aqueles envolvendo o balanced scorecard, por exemplo.

Para fins deste estudo, utilizaram-se as práticas apresentadas por Guilding, Cravens e Tayles (2000), que determinaram os seguintes parâmetros para discernir as práticas de Contabilidade Estratégica: (a) orientação para o mercado ou ambiente externo; (b) enfoque sobre competidores e (c) orientação para o futuro de longo prazo.

Com esses parâmetros, Guilding, Cravens e Tayles (2000) abstraíram 12 práticas de Contabilidade, cuja incidência e mérito foram testadas em grandes empresas dos Estados Unidos, Reino Unido e Nova Zelândia e serão replicadas neste estudo. As práticas são descritas, em síntese, a seguir: 
1) Custeio dos atributos

Consiste no processo de valorização dos atributos do produto pelos clientes e, por isso, esses passam a serem vistos como objetos de custo. A relação entre os atributos do produto e as escolhas dos clientes determina a participação da empresa no mercado. Conforme Bromwich (1990) apud Guilding, Cravens e Tayles (2000), essa prática se materializa em prática de Contabilidade Estratégica por meio da aplicação da teoria da análise dos atributos, a qual percebe os produtos como um bem econômico que tem valor para os consumidores por meio dos atributos ou características que apresentam e por isso devem ser monitorados. Exemplos de atributos incluem: variáveis de desempenho operacional, confiabilidade e contratos de garantia, grau de acabamento, garantia de fornecimento e serviços pósvendas.

Lord (1996) comenta que essa abordagem tem relação com as estratégias genéricas de Porter: diferenciação, relacionada à teoria da análise dos atributos; e a liderança no custo, relacionada à teoria dos mercados disputáveis.

2) Avaliação e monitoramento da marca

Em empresas com marcas fortes, cujos produtos são reconhecidos pelos consumidores, a avaliação $e$ o monitoramento da marca representam oportunidades para medição do potencial para atingir novos mercados, ao associar fatores estratégicos como: liderança, estabilidade, mercado, internacionalidade e proteção associados aos lucros históricos da marca. Como resultado, as estratégias recaem sobre a natureza do mercado da marca (alta competitividade devido a produtos similares, por exemplo, no qual as vantagens competitivas são temporárias) e posição no mercado, o qual considera um conjunto de fatores com vistas ao crescimento ou à proteção da marca. (GRZESZEZESZYN, 2004).

3) Orçamento do valor da marca

A monitoração do valor da marca pode ser considerada de grande importância para a função marketing da empresa, pois permite utilizar o valor financeiro da marca como base para alocação de recursos com vistas a fortalecer ou acrescer a sua participação no mercado. Conseqüentemente, o valor da marca como prática de Contabilidade Estratégica pode contribuir nas decisões administrativas sobre as alocações de recursos para suportar/realçar a posição estratégica da empresa.

4) Avaliação do custo dos competidores

Em função da acirrada concorrência que caracteriza o mercado na atualidade, a análise dos custos dos competidores permite assegurar tomada de decisões que garantam a continuidade sustentada das atividades empresariais. Para tanto, o sistema de informações da empresa deve estar preparado para prover informações que facilitem o processo de concepção, desenvolvimento, implementação e monitoramento de estratégias competitivas tendo por base, além da gestão dos custos da empresa, a avaliação de como se comportam os custos de seus principais competidores com a utilização de fontes indiretas, como fornecedores e clientes comuns, empregados e ex-empregados, dentre outras, com vista a propiciar maior detalhamento, percepções e estimativas a respeito do custo dos competidores ante os custos da empresa.

5) Monitoramento da posição competitiva

Para esse item, os autores definem monitoração da posição competitiva como a análise da posição do competidor pela apreciação e monitoramento das tendências sobre as vendas, da participação de mercado, do volume e custo por unidade, dos gastos realizados e do retorno sobre as vendas. Para Simmonds (1986) apud Guilding, Cravens e Tayles (2000), consiste numa avaliação mais abrangente do que o custo dos competidores e visa identificar como os competidores estão se comportando em relação ao mercado, provendo informações relacionadas à estratégia do competidor.

Ao se avaliarem e monitorarem os custos e posição dos competidores, busca-se identificar possíveis vantagens competitivas em contraste com a empresa, o que acaba auxiliando no conhecimento da própria organização, posto que a comparação entre forças e fraquezas, o vislumbrar das oportunidades e ameaças, acabam por estabelecer um grau de atenção constante para a posição dos competidores e da própria organização. (GRZESZEZESZYN, 2004).

6) Avaliação das demonstrações financeiras dos competidores

Consiste na análise numérica das demonstrações financeiras dos competidores como parte de uma avaliação das fontes-chaves de vantagem competitiva dos competidores. Essa avaliação deve ir além da análise convencional de demonstrações financeiras, permitindo que se considerem aspectos relacionados ao ambiente de mercado com vistas a evidenciar fontes de vantagem competitiva a partir da análise das estratégias dos competidores que possam identificar: (a) os contextos interno e externo em que o competidor atua; b) o desempenho obtido em anos anteriores, para suscitar possíveis tendências em vendas, lucros, movimentos de ativos e passivos, dentre outros; $c$ ) as taxas ou coeficientes utilizados como balizadores dos objetivos estratégicos; d) e a interpretação dessas taxas ou coeficientes para descobrir qual foi o desempenho do competidor naqueles fatores-chaves para a sua estratégia. 
7) Custeio do ciclo de vida

O custeio do ciclo de vida consiste em atribuir custos ao longo da existência do produto, ou seja, em vez de avaliar custos em uma base anual, avalia-se considerando o período de tempo relativo às fases do produto. Essas podem incluir projeto, desenvolvimento, crescimento, maturidade, declínio e descarte final. Essa atribuição de custos ao longo das fases do ciclo de vida possibilita informações importantes para a determinação de preços, trazendo como conseqüência a recuperação dos custos das atividades da cadeia de valor. A exigência de uma apreciação do mercado para o produto é latente para esse tipo de custeio, uma vez que deve ser considerado o tempo em que os concorrentes conseguem introduzir produto semelhante ou apresentar inovações.

8) Custeio da qualidade

O controle da qualidade tem conseqüências estratégicas, uma vez que traz efeitos de longo prazo, cuja base é a relação com fornecedores e clientes. Abordar o custeio da qualidade pode trazer vantagens estratégicas para a empresa, dado que os gastos com prevenção podem redundar em redução dos custos de falhas e permitir a fidelização dos clientes. Guilding, Cravens e Tayles (2000) comentam que a qualidade do produto ou de serviço pode ser uma fonte de vantagem competitiva.

\section{9) Custeio estratégico}

Guilding, Cravens e Tayles (2000) definem custeio estratégico como o uso de dados de custo baseado em informações mercadológicas e estratégicas para desenvolver e identificar estratégias superiores que produzirão uma vantagem competitiva sustentável. No custeio estratégico devem ser identificadas as combinações de fatores que, inter-relacionados de forma complexa e de diferentes maneiras, dão origem a situações específicas nas quais os custos emergem. Dessa forma, a compreensão do comportamento dos custos de uma determinada área ou situação de negócio leva ao conhecimento das inter-relações existentes no conjunto dos geradores de custo que exercem influência sobre essa determinada área ou situação. Para Shank e Govindarajan (1997), o custeio estratégico apresenta um escopo mais abrangente que permite utilizá-las para se auferirem vantagens competitivas sustentáveis, mostrando a importância estratégica das informações de custos disponíveis à operação.

10) Precificação estratégica

A precificação estratégica é a atividade preocupada com a colocação de preços para novos produtos e 0 ajuste de preços para produtos existentes e faz parte do composto mercadológico, que do ponto- de-vista do consumidor, é elemento inseparável do produto (bem ou serviço). É através dessa relação que o consumidor pode avaliar a relação custo-benefício ou, em outros termos, sua possibilidade de extrair valor do dinheiro por ele despendido.

Assim, a estratégia de precificação é o elemento de tomada de decisão da empresa preocupado com o estabelecimento de preços que atrairão o mercado-alvo, permitindo, assim, alcançar os objetivos de lucro. Na definição de sua estratégia, a empresa defronta-se com algumas opções que irão orientar sua política, em termos de quais variáveis serão predominantes na sua determinação, considerando a concepção do cliente (capacidade da demanda, posição do produto no seu ciclo de vida e características comportamentais do consumidor), dos competidores (preços de produtos semelhantes praticados por seus competidores) e dos custos.

11) O custeio meta

Um processo no qual um produto é projetado para satisfazer um cliente específico, com um custo predeterminado, cujo intuito é atingir um lucro meta. Swenson et al. (2003) apud Guilding, Cravens e Tayles (2000) apresentam os princípios-chaves do custeio meta: a) custeio baseado no preço de mercado; b) foco nas exigências dos clientes; c) foco sobre projeto e os custos para sua execução; d) envolvimento funcional cooperativo; e) envolvimento da cadeia de valor $e$ f) orientação para o ciclo de vida, em que os custos são minimizados tanto para o produtor quanto para o consumidor. Os autores comentam, ainda, que o custeio Kaizen utiliza processo semelhante, à medida que se configura como um esforço constante para reduzir custos. A abordagem estratégica dessa prática está na relação com o mercado com vistas à obtenção de vantagem competitiva.

12) Custeio da cadeia de valor

A perspectiva da cadeia de valor de Porter inserese numa visão horizontal dos negócios da empresa, sendo um conjunto complexo de ligações e relacionamentos entre os componentes da cadeia de valor, que vai do projeto do produto à estrutura de distribuição. Shank e Govindarajan (1997) propõem uma abordagem para custeio que se fundamente na análise da cadeia de valor, de modo a identificar e manter vantagens competitivas ao longo dela. Consideram que a análise da cadeia de valor deve começar com o fornecedor do fornecedor e avançar para o cliente do cliente, entendendo a empresa como parte de uma cadeia maior do setor econômico. Essa percepção torna-se relevante à medida que possibilita redução dos custos para a empresa, bem como acresce valor para o cliente ao longo das atividades da cadeia de valor. 


\section{METODOLOGIA}

\subsection{Delineamento da Pesquisa}

Tendo em vista que este estudo medirá a percepção dos docentes dos programas de pós-graduação stricto sensu em Ciências Contábeis do Brasil quanto a questões relacionadas à Contabilidade Estratégica, a pesquisa caracterizase como descritiva, de acordo com a classificação de Gil (1999), à medida em que descreverá as atitudes e opiniões dos respondentes.

Para que o objetivo proposto fosse atingindo, o procedimento de pesquisa utilizado, ou seja, a maneira pela qual se conduziu o estudo e se obtiveram os dados, foi o levantamento por meio de questionário. De acordo com Gil (1999), as pesquisas de levantamento se caracterizam pela interrogação direta das pessoas cujo comportamento, atitudes e opiniões se desejam conhecer.

Assim sendo, utilizou-se um questionário baseado nas pesquisas de Guilding, Cravens e Tayles (2000) e de Grzeszezeszyn e Ferreira (2004), contendo as seguintes questões:

1) Antes de responder a este questionário você considera que tinha uma forte compreensão do significado do termo "Contabilidade Estratégica"? Uma escala Likert de 1 a 7 registrou as respostas para essa pergunta, na qual o ponto 1 significava "discordo totalmente"; 2 "discordo muito"; 3 "discordo pouco"; 4 "não discordo, nem concordo"; 5 "concordo pouco"; 6 "concordo muito" e o 7 "concordo totalmente", para medir o grau de compreensão dos pesquisados.

2) O termo "Contabilidade Estratégica" é usado em sua atividade profissional? Novamente as respostas foram registradas em uma escala Likert variando de 1 a 7 , para registrar a medida de uso pelos respondentes.

3) Em que você considera que as seguintes práticas poderiam ser úteis para as empresas? Logo abaixo foram listadas as doze práticas de Contabilidade Estratégica apontadas por Guilding, Cravens e Tayles (2000) e, ao lado de cada prática, foi colocada a escala Likert de 1 a 7 , com os seguintes significados para os pontos: 1 "totalmente inútil"; 2 "muito inútil"; 3 "pouco inútil"; 4 "nem útil, nem inútil"; 5 "pouco útil"; 6 "muito útil" e 7 "totalmente útil", para registrar a medida de mérito de cada prática de acordo com a opinião dos respondentes.

É importante frisar que a escala Likert, originalmente, assume valores de 1 a 5. Contudo, Guilding, Cravens e Tayles (2000) e Grzeszezeszyn e Ferreira (2004) utilizaram uma escala variando de 1 a 7 . Assim, optou-se por seguir a mesma escala de 1 a 7 para efeito de comparação dos resultados com aquelas pesquisas.

Não se realizou a etapa de pré-teste do questionário para o enfoque deste estudo, tendo em vista que ele já havia sido validado nas pesquisas anteriores de Guilding,
Cravens e Tayles (2000) e Grzeszezeszyn e Ferreira (2004), as quais constataram sua consistência nos pré-testes então realizados. As únicas alterações feitas no questionário foram a adequação das questões para atender o público alvo, uma vez que naqueles estudos os pesquisados apresentam uma visão "de dentro" da empresa e neste uma visão "de fora" da empresa.

O questionário com as três perguntas foi disponibilizado aos respondentes em uma home page, no período de 15 de abril a 20 de maio de 2006, na qual foi apensado, ainda, um glossário de termos, no qual constaram, em síntese, os significados das práticas de Contabilidade Estratégica.

Um correio eletrônico foi enviado aos docentes convidando-os a participar da pesquisa. O e-mail continha uma carta de apresentação e o endereço da home page com o questionário. Durante o período em que o questionário ficou disponível, três correios eletrônicos adicionais foram enviados.

\subsection{População e Amostra}

A população da pesquisa compreendeu todos os docentes dos cursos de pós-graduação stricto sensu em Ciências Contábeis existentes no Brasil em março de 2006. abrangendo os cursos de doutorado e mestrado, acadêmicos e profissionais, reconhecidos pela CAPES - Fundação Coordenação de Aperfeiçoamento de Pessoal de Nível Superior.

Conforme dados da CAPES, existiam, no Brasil, quatorze programas de pós-graduação stricto sensu em Ciências Contábeis devidamente reconhecidos à época deste estudo, conforme Quadro 10.

Para obter o quantitativo de docentes dos programas pesquisados, acessou-se a página na Internet de cada programa. Adicionalmente, recorreu-se ao Currículo Lattes dos docentes disponíveis na base de dados do CNPq (ConseIho Nacional de Desenvolvimento Científico e Tecnológico) para selecionar aqueles ministrantes de disciplinas relacionadas à Contabilidade e seus e-mails de contato.

Não fizeram parte do levantamento, os docentes do programa da Universidade Federal do Amazonas, em função de o reconhecimento do curso ter ocorrido no decorrer do desenvolvimento deste estudo (reconhecido em 22 de março de 2006).

Com isso, apurou-se um público-alvo de 104 docentes. Dos docentes contatados por correio eletrônico, 2 não receberam o questionário devido a falhas na entrega e 43 apresentaram respostas válidas, perfazendo uma taxa de retorno dos questionários da ordem de 41,3\%. Tal percentual pode ser considerado bom, pelo menos no Brasil, em função do histórico de pequeno percentual de retorno de questionários, adequadamente, respondidos nesse tipo de abordagem, conforme apontam Marconi e Lakatos (1999). A composição do público-alvo é mostrada na Tabela 10 .

Para efeito de comparação, na pesquisa de Guilding, Cravens e Tayles (2000), a taxa de retorno dos questio- 


\begin{tabular}{|l|l|l|l|}
\hline \multicolumn{1}{|c|}{ PROGRAMAS DE PÓS-GRADUAÇÃO } & \multicolumn{1}{|c|}{ INSTITUIÇÃO } & UF & \multicolumn{1}{c|}{ TIPO } \\
\hline Contabilidade e Controladoria & UFAM & AM & Mestrado Profissional \\
\hline Controladoria & UFC & CE & Mestrado Profissional \\
\hline Ciências Contábeis & UnB/UFPE/UFPB/UFRN & DF & Doutorado e Mestrado Acadêmico \\
\hline Ciências Contábeis & FUCAPE & ES & Mestrado Profissional \\
\hline Contabilidade & UFPR & PR & Mestrado Acadêmico \\
\hline Ciências Contábeis & UERJ & RJ & Mestrado Acadêmico \\
\hline Ciências Contábeis & UFRJ & RJ & Mestrado Acadêmico \\
\hline Ciências Contábeis & UNISINOS & RS & Mestrado Acadêmico \\
\hline Ciências Contábeis & FURB & SC & Mestrado Acadêmico \\
\hline Contabilidade & UFSC & SC & Mestrado Acadêmico \\
\hline Ciências Contábeis e Atuarias & PUC & SP & Mestrado Acadêmico \\
\hline Controladoria e Contabilidade Estratégica & UNIFECAP & SP & Mestrado Acadêmico \\
\hline Controladoria e Contabilidade & USP & SP & Doutorado e Mestrado Acadêmico \\
\hline Controladoria e Contabilidade & USP/RP & SP & Mestrado Acadêmico \\
\hline
\end{tabular}

Fonte: CAPES. Disponível em: <www.capes.gov.br>. Acesso em: 28.03.2006.

Nota: atualmente o Brasil conta com dezessete programas de pós-graduação em Ciências Contábeis, com a aprovação pela CAPES, após a conclusão deste estudo, dos programas de mestrado acadêmico da UFBA, UFMG e UFPE.

Quadro 1 || Relação dos Programas de Pós-Graduação em Ciências Contábeis

Tabela 1 Status dos Questionários

\begin{tabular}{l|c|c|c|c} 
Descrição & Enviados & Respondidos & Não Confirmados & Com Falhas \\
Geral & 104 & 43 & 59 & 2 \\
\hline Sul & 30 & 13 & 17 & 0 \\
\hline Sudeste & 55 & 20 & 33 & 2 \\
\hline Nordeste & 5 & 2 & 3 & 0 \\
\hline Centro-Oeste & 14 & 8 & 6 & 0
\end{tabular}

Fonte: Elaborada pelos autores

nários válidos ficou em 23\% (questionários enviados para 1.292 empresas, sendo obtidas 297 respostas válidas) e na de Grzeszezeszyn e Ferreira (2004), de 19\% (100 empresas contatas e 19 respostas obtidas).

Ressalte-se que, para o Programa Multiinstitucional e Inter-regional da UnB/UFPE/UFPB/UFRN, foi considerada a origem dos respondentes como sendo o Centro-Oeste, apesar de o Programa possuir docentes oriundos de várias instituições do Nordeste. Dessa forma, considerando a Região dos respondentes, a distribuição percentual é mostrada no Gráfico 10.

Com esse número de respondentes, a margem de erro estabelecida para as inferências estatísticas ficou em 10\%, ou seja, o alfa de significância é igual a 0,10. Com isso, os resultados encontrados podem ser considerados corretos ao nível de confiança de $90 \%$.

Uma vez que os resultados podem ser tanto maiores quanto menores, ou seja, um teste bicaudal, o alfa a ser considerado nos testes é de 0,05, isto é, 0,10 dividido por dois, perfazendo o percentual em cada cauda da curva de probabilidade. Com isso, o valor $Z$ considerado será $+/-1,64$.

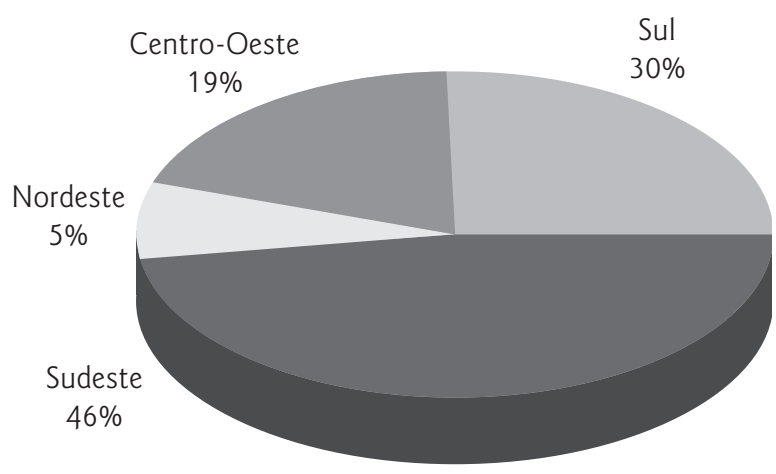

Fonte: Elaborado pelos autores

Gráfico 1 | Região dos Respondentes

\subsection{Tratamento dos Dados e Limitações do Método}

Os dados coletados foram tratados de forma quantitativa e para facilitar a análise, as doze práticas de Contabilidade Estratégica foram divididas em três categorias, de 
acordo com afinidades: a) Práticas de Custeio e Precificação Estratégica: Custeio dos Atributos, Custeio do Ciclo de Vida, Custeio da Qualidade, Custeio Estratégico, Custeio Meta; Custeio da Cadeia de Valor e Precificação Estratégica; b) Práticas de Análises dos Competidores: Avaliação do Custo dos Competidores, Monitoração da Posição Competitiva e Avaliação dos Competidores Baseada em Demonstrações Financeiras Publicadas; c) Práticas de Avaliação e Monitoramento da Marca: Orçamento do Valor da Marca e Monitoração do Valor da Marca.

A partir da tabulação dos dados, os escores atribuídos por todos os respondentes foram analisados por meio da estatística descritiva, com a indicação das médias, medianas, variâncias e desvios-padrão. Para o estudo comparativo, foi realizado um teste para verificar a aderência dos dados à distribuição normal e suportar a decisão pela utilização de técnicas paramétricas ou não-paramétricas para análises das diferenças de médias ou medianas. $O$ teste utilizado foi o Shapiro-Willk, apropriado para amostras menores ou iguais a 50 componentes. (MAROCO, 2003, p. 114).

Para todas as variáveis, foram obtidos resultados inferiores ao alfa de significância de 0,10 estabelecido (maior $p$-value observado foi igual a 0,036 ), mostrando, conforme Maroco (2003, p. 113), que as variáveis não poderiam ser tratadas pela distribuição normal e, assim sendo, testes não-paramétricos seriam os mais recomendados.

Em que pese a indicação de testes não-paramétricos, eles não puderam ser aplicados integralmente em função da indisponibilidade dos dados abertos da pesquisa de Guilding, Cravens e Tayles (2000), sendo utilizada a estatística descritiva, para esse caso. Já o teste de Mann-Whitney foi utilizado para se analisar se existem diferenças significativas entre as médias das percepções dos docentes e aquelas obtidas por Grzeszezeszyn e Ferreira (2004) com controllers de grandes empresas brasileiras. O teste de Mann-Whitney foi realizado utilizando o software estatístico SPSS - Statistical Package for the Social Sciences, versão 10.0.

De acordo com Martins (2006, p. 269), o teste de Mann-Whitney é usado para testar se duas amostras independentes foram retiradas de populações com médias iguais, sendo testadas as seguintes hipóteses:

$H_{0}=$ não existe diferença entre os grupos, ou seja, as médias são iguais;

$\mathrm{H}_{1}$ = há diferença entre os grupos, ou seja, as médias não são iguais.

O teste de Mann-Whitney baseia-se numa soma de postos, ou classificações. Quando $\mathrm{H}_{0}$ é verdadeira, os postos devem distribuir-se de forma equilibrada entre as duas amostras. Para $\mathrm{H}_{1}$ ser verdadeira uma amostra tenderá a ter mais postos baixos e, conseqüentemente, uma soma de postos menor, enquanto a outra tenderá a uma soma de postos maior.

Dentre as limitações do método, além da indisponibilidade dos dados, é importante frisar que é inerente aos tipos de pesquisas realizadas por meio de levantamentos com a utilização de questionários, que os resultados apresentados podem não representar a realidade em alguns aspectos, posto que são percepções dos respondentes no momento do preenchimento do questionário, as quais podem ter sido influenciadas pelo entendimento incompleto das proposições ou dos significados dos escores da escala utilizada.

Além disso, ressalte-se que os resultados das três pesquisas realizadas e comparadas podem estar enviesadas pelas diferenças culturais dos respondentes, altamente diversas, ou seja, profissionais de empresas situadas em países desenvolvidos versus profissionais de empresas situadas nas regiões mais desenvolvidas do Brasil versus professores de diversas regiões brasileiras. Portanto, algumas conclusões podem conter esse viés.

\section{RESULTADOS E DISCUSSÕES}

Passados mais de dez anos em que autores como Goldenberg (1994) e Coad (1996) apontavam a Contabilidade Estratégica como um campo emergente, do qual os limites ainda eram desconhecidos e que não existia uma visão unificada do que é ou como ela poderia se desenvolver, é de se esperar que os resultados dessa pesquisa apontem para uma melhoria nessa percepção indicada pelos autores.

Nesse contexto, as médias obtidas acima de 4 (pontuação variando de 1 a 7) sugerem que os aspectos relacionados à Contabilidade Estratégica caminham para a consolidação quanto à compreensão, ao uso e à importância; enquanto médias menores que 4 evidenciam que ainda existe um hiato como apontado por Goldenberg e Coad e que precisa ser resolvido em relação ao que realmente vem a ser a Contabilidade Estratégica e a sua utilidade.

Considerando os resultados obtidos para a compreensão do termo "Contabilidade Estratégica", a média geral obtida foi de 5,14, indicando que os respondentes consideram que tinham certa compreensão do termo. Contudo, fica claro que o tema ainda não é totalmente pacífico ao se observar que o desvio-padrão foi relativamente alto $(1,47)$. Desconsiderando os valores extremos pontuados pelos respondentes, a mediana ficou em 6,00 (concordo muito).

Levando em conta os resultados por região, destaca-se a média aritmética do Centro-Oeste (4,25), a qual foi a menor em relação às demais e a que apresentou maior dispersão nas pontuações, com desvio-padrão de 1,58. Esse resultado reforça a tese de que a questão ainda precisa ser mais bem disseminada e delimitada. $O$ resultado consolidado da primeira questão investigada consta da Tabela $2 \boldsymbol{0}$.

Considerando os resultados obtidos na primeira questão, há de se esperar que os resultados para o uso do termo nas atividades profissionais dos pesquisados ficassem abaixo daqueles apresentados na Tabela 2. 
Tabela 2 || Medidas de Compreensão do Termo “Contabilidade Estratégica”

\begin{tabular}{l|c|c|c|c} 
Descrição & Média & Desvio-Padrão & Variância & Mediana \\
Geral & 5,14 & 1,47 & 2,17 & 6,00 \\
\hline Sul & 5,38 & 1,26 & 1,59 & 6,00 \\
\hline Sudeste & 5,25 & 1,52 & 2,30 & 6,00 \\
\hline Nordeste & 6,00 & 1,41 & 2,00 & 6,00 \\
\hline Centro-Oeste & 4,25 & 1,58 & 2,50 & 4,50
\end{tabular}

Fonte: Elaborada pelos autores

Conseqüentemente, os resultados obtidos para a segunda questão mostram que o uso do termo "Contabilidade Estratégica" é relativamente baixo, com média aritmética de 4,02 e desvio-padrão de 1,68, evidenciando, novamente, uma forte variabilidade nas pontuações dadas pelos respondentes.

Analisando sob o prisma regional, a média das pontuações variou de 3,13 para o Centro-Oeste a 5,50 para o Nordeste, o mesmo acontecendo com o desvio-padrão, 1,13 e 2,12, respectivamente. O resultado consolidado da segunda questão investigada consta da Tabela $3 \boldsymbol{0}$.

Lord (1996), em análise sobre o uso de práticas de Contabilidade Estratégica, argumenta que tais práticas podem estar sendo confundidas e/ou entendidas como aquelas referentes a práticas de Contabilidade Gerencial tradicional, ou o seu uso esteja restrito a profissionais da alta administração que não necessariamente os controllers.

Em relação à terceira questão do estudo, o objetivo era medir o mérito de certas práticas de Contabilidade Estra- tégica quanto à utilidade para as empresas, na opinião dos docentes respondentes. Médias acima de 4 sugerem que a prática relacionada apresenta certa utilidade para a empresa em criar vantagem competitiva e clarificar o seu plano estratégico, conforme Dixon (1998); enquanto médias menores que 4 evidenciam que a prática relacionada não apresenta medida de utilidade suficiente.

$\mathrm{Na}$ amostra geral, todas as práticas de custeio e precificação estratégica constante da Tabela $4 \mathbf{O}$ tiveram médias aritméticas maior que 5 . A mediana dessas práticas foi o ponto 6 (concordo muito), com exceção da prática "custeio de atributos", que obteve mediana igual a 5 (concordo pouco).

Segundo os docentes pesquisados, a prática do "custeio da cadeia de valor" consiste na mais relevante desse agrupamento, com média de 5,79, enquanto as práticas "custeio dos atributos" e "custeio estratégico" foram as que apresentaram menores escores médios, ambas com 5,14 de média.

Tabela 3 | Medidas do Uso do Termo “Contabilidade Estratégica”

\begin{tabular}{l|c|c|c|c} 
Descrição & Média & Desvio-Padrão & Variância & Mediana \\
Geral & 4,02 & 1,68 & 2,83 & 4,00 \\
\hline Sul & 3,92 & 1,55 & 2,41 & 4,00 \\
\hline Sudeste & 4,30 & 1,84 & 3,38 & 5,00 \\
\hline Nordeste & 5,50 & 2,12 & 4,50 & 5,50 \\
\hline Centro-Oeste & 3,13 & 1,13 & 1,27 & 3,00
\end{tabular}

Fonte: Elaborada pelos autores

Tabela 4 || Medidas do Mérito das Práticas de Custeio e Precificação Estratégica

\begin{tabular}{|c|c|c|c|c|c|c|c|c|c|c|c|}
\hline \multirow[b]{2}{*}{ Descrição } & \multicolumn{3}{|c|}{ GERAL } & \multicolumn{2}{|c|}{ SUL } & \multicolumn{2}{|c|}{ SUDESTE } & \multicolumn{2}{|c|}{ NORDESTE } & \multicolumn{2}{|c|}{ CENTRO-OESTE } \\
\hline & $\begin{array}{l}\frac{\pi}{7} \\
\stackrel{0}{\Sigma}\end{array}$ & 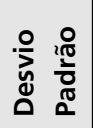 & 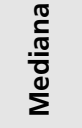 & $\frac{\pi}{\frac{\pi}{8}}$ & 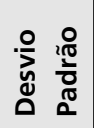 & $\begin{array}{l}\frac{\pi}{\pi} \\
\stackrel{0}{\Sigma}\end{array}$ & 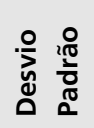 & $\begin{array}{l}\frac{\pi}{7} \\
\stackrel{0}{\Sigma}\end{array}$ & 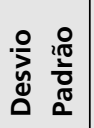 & $\frac{.0}{\frac{\pi}{0}}$ & 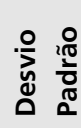 \\
\hline Custeio de Atributos & 5,14 & 1,44 & 5,00 & 5,62 & 1,39 & 5,00 & 1,45 & 6,00 & 1,41 & 4,50 & 1,41 \\
\hline Custeio do Ciclo de Vida & 5,40 & 1,42 & 6,00 & 5,54 & 1,27 & 5,35 & 1,57 & 6,00 & 1,41 & 5,13 & 1,46 \\
\hline Custeio da Qualidade & 5,37 & 1,50 & 6,00 & 5,62 & 1,19 & 5,45 & 1,50 & 6,00 & 1,41 & 4,63 & 1,92 \\
\hline Custeio Estratégico & 5,14 & 1,85 & 6,00 & 5,08 & 2,01 & 5,45 & 1,61 & 6,50 & 0,71 & 4,13 & 2,10 \\
\hline Custeio Meta & 5,56 & 1,33 & 6,00 & 5,92 & 0,86 & 5,65 & 1,27 & 6,50 & 0,71 & 4,50 & 1,77 \\
\hline Custeio da Cadeia de Valor & 5,79 & 1,15 & 6,00 & 5,92 & 0,95 & 5,85 & 1,09 & 6,00 & 1,41 & 5,38 & 1,60 \\
\hline Precificação Estratégica & 5,47 & 1,58 & 6,00 & 5,38 & 1,85 & 5,75 & 1,12 & 6,50 & 0,71 & 4,63 & 2,07 \\
\hline
\end{tabular}


Observa-se, novamente, uma grande dispersão das pontuações. A prática com menor dispersão foi o "custeio da cadeia de valor”, com desvio-padrão igual a 1,15, enquanto a prática do "custeio estratégico" foi a que apresentou maior dispersão, com desvio-padrão de 1,85.

As práticas do agrupamento de custeio e precificação estratégica sugerem uma preocupação com a eficiência $e$ manutenção ou melhoria da posição competitiva, por meio de informações que contemplem dados de custos.

As empresas podem desenvolver e manter estratégias de custos do tipo "vantagem de baixo custo" ou "diferenciação com vantagem de custo" e a escolha sobre esses tipos, conforme Shank e Govindarajan (1997, p. 61), vai depender de como a empresa gerencia sua cadeia de valor em relação às cadeias de valor de seus concorrentes, ou seja, a vantagem competitiva dependerá de se a empresa oferece mais valor ao cliente por um custo equivalente (isto é, diferenciação) ou valor equivalente por um custo inferior (isto é, baixo custo). Com isso, a análise da cadeia de valor é essencial para determinar exatamente onde, na cadeia de valor do cliente, o valor pode ser aumentado ou os custos reduzidos.

O segundo agrupamento das práticas de Contabilidade Estratégica refere-se à análise dos competidores e os resultados obtidos podem ser verificados na Tabela $5 \mathbf{O}$. A percepção de utilidade dessas práticas ficou situada no escore médio para cima e a prática "monitoramento da posição competitiva" e "avaliação dos custos dos competidores" foram as que apresentaram maiores médias, 5,86 e 5,67. respectivamente, o mesmo ocorrendo para os agrupamentos regionais. As dispersões nos escores estiveram presentes novamente.
A prática "avaliação dos competidores baseada em demonstrações financeiras" foi a menos pontuada, inclusive, ao se analisar a pontuação dos docentes do Centro-Oeste, a qual ficou abaixo do ponto central. Talvez os pesquisados tenham percebido essa prática como um artefato tradicional e não como uma prática que se materialize como um item estratégico relevante, mas o que se espera com essa prática é permitir que se consiga relacionar, adequadamente, as fontes-chaves de vantagem competitiva dos competidores por meio de uma análise estruturada das suas demonstrações contábeis.

O último agrupamento das práticas de Contabilidade Estratégica refere-se à avaliação e monitoramento da marca. Os escores obtidos nesse agrupamento situaram-se do ponto médio para cima, mostrando que essas práticas possuem certo mérito na estratégia competitiva das empresas. Mais uma vez, as dispersões dos escores obtidos foram altas, indicando que ainda existe espaço para aperfeiçoamento de como a Contabilidade Estratégica pode se desenvolver para contribuir na formulação do planejamento estratégico, com a obtenção de vantagem competitiva por meio da manutenção ou crescimento da participação da marca no mercado. Os resultados constam da Tabela $6 \mathbf{0}$.

De modo geral, os resultados obtidos para as três questões pesquisadas mostram que os escores marcados pelos docentes ficaram acima do ponto médio, indicando uma certa compreensão do termo "Contabilidade Estratégica", aliada a um uso menos intenso do termo. As práticas relacionadas de Contabilidade Estratégica apontam como medidas que podem levar as empresas a obter e manter vantagens competitivas.

Tabela 5 Medidas do Mérito das Práticas de Análises dos Competidores

\begin{tabular}{|c|c|c|c|c|c|c|c|c|c|c|c|}
\hline \multirow[b]{2}{*}{ Descrição } & \multicolumn{3}{|c|}{ GERAL } & \multicolumn{2}{|c|}{ SUL } & \multicolumn{2}{|c|}{ SUDESTE } & \multicolumn{2}{|c|}{ NORDESTE } & \multicolumn{2}{|c|}{ CENTRO-OESTE } \\
\hline & $\frac{\pi}{\frac{\pi}{g}}$ & 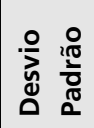 & $\begin{array}{l}\frac{\pi}{c} \\
\frac{\pi}{\pi} \\
\frac{\pi}{\delta} \\
\Sigma\end{array}$ & $\begin{array}{l}\frac{\pi}{7} \\
\stackrel{0}{\alpha}\end{array}$ & 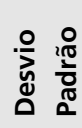 & $\frac{\frac{\pi}{7}}{\stackrel{0}{2}}$ & 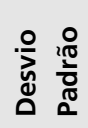 & $\frac{\frac{\pi}{0}}{\frac{\pi}{0}}$ & 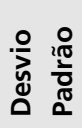 & $\frac{\frac{\pi}{7}}{\sum^{\frac{\pi}{2}}}$ & 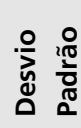 \\
\hline Avaliação do Custo dos Competidores & 5,67 & 1,19 & 6,00 & 5,92 & 0,86 & 5,80 & 1,11 & 6,00 & 1,41 & 4,88 & 1,64 \\
\hline Monitoramento da Posição Competitiva & 5,86 & 1,15 & 6,00 & 6,15 & 0,80 & 6,00 & 0,97 & 6,00 & 1,41 & 5,00 & 1,69 \\
\hline $\begin{array}{l}\text { Avaliação das Demonstrações } \\
\text { Financeiras dos Competidores }\end{array}$ & 4,86 & 1,42 & 5,00 & 5,15 & 0,90 & 5,10 & 1,48 & 6,00 & 1,41 & 3,50 & 1,31 \\
\hline
\end{tabular}

Fonte: Elaborada pelos autores

Tabela 6 - Medidas do Mérito das Práticas de Avaliação e Monitoramento da Marca

\begin{tabular}{|c|c|c|c|c|c|c|c|c|c|c|c|}
\hline \multirow[b]{2}{*}{ Descrição } & \multicolumn{3}{|c|}{ GERAL } & \multicolumn{2}{|c|}{ SUL } & \multicolumn{2}{|c|}{ SUDESTE } & \multicolumn{2}{|c|}{ NORDESTE } & \multicolumn{2}{|c|}{ CENTRO-OESTE } \\
\hline & $\frac{.0}{\bar{\pi}}$ & 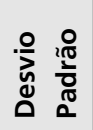 & 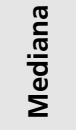 & 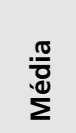 & 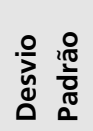 & $\frac{.0}{\frac{\pi}{0}}$ & 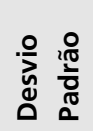 & $\begin{array}{l}\frac{\pi}{7} \\
\stackrel{0}{\alpha}\end{array}$ & 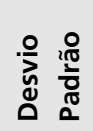 & $\frac{. \pi}{\frac{\pi}{7}}$ & 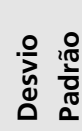 \\
\hline Avaliação e Monitoramento da Marca & 5,14 & 1,37 & 5,00 & 5,23 & 1,36 & 5,30 & 1,08 & 6,50 & 0,71 & 4,25 & 1,83 \\
\hline Orçamento do Valor da Marca & 4,95 & 1,41 & 5,00 & 5,08 & 1,04 & 5,00 & 1,41 & 6,50 & 0,71 & 4,25 & 1,83 \\
\hline
\end{tabular}

Fonte: Elaborada pelos autores 
Relevante observar, entretanto, que a dispersão nos escores obtidos foi elevada, corroborando o que foi discutido ao longo do referencial de base, no que diz respeito à Contabilidade Estratégica tratar-se de um campo em expansão, cujos conceitos envolvidos ainda precisam ser delineados e explicitados, adequadamente, para a sua correta compreensão a aplicação.

Para exemplificar, em relação à compreensão do termo "Contabilidade Estratégica", observou-se que o escore 7 foi pontuado sete vezes, ao mesmo tempo que o escore 2 (menor escore pontuado), quatro vezes, ou seja, sete docentes da amostra concordaram totalmente que possuíam uma forte compreensão do termo e quatro discordaram muito que possuíam a sua compreensão.

Talvez isso possa explicar as mais altas dispersões observadas nos resultados obtidos para as práticas de "custeio estratégico" e "precificação estratégica": nove docentes discordaram quanto ao mérito da prática do "custeio estratégico" para a Contabilidade Estratégica e três discordaram totalmente, dois discordaram muito e quatro discordaram pouco, ao passo que trinta docentes concorda- ram que tal prática era relevante para as empresas (cinco concordaram pouco; quatorze, muito e onze, totalmente).

\subsection{Estudo Comparativo}

As Tabelas $70,8 \boldsymbol{0}, 90$ e 100 apresentam os resultados das pesquisas realizadas por Guilding, Cravens e Tayles (2000) e Grzeszezeszyn e Ferreira (2004) com profissionais de grandes empresas, comparadas com os resultados obtidos junto aos docentes objeto do estudo.

Os valores representam as pontuações médias dos respondentes. Nas colunas "Nova Zelândia", "Reino Unido" e "Estados Unidos" constam os resultados apurados por Guilding, Cravens e Tayles e na coluna "Sul e Sudeste Brasil”, os apurados por Grzeszezeszyn e Ferreira. Tais médias representam as percepções dos controllers. Na última coluna constam as percepções dos docentes/professores.

A primeira constatação (Tabela 7) entre a percepção dos controllers e dos docentes quanto à compreensão do termo "Contabilidade Estratégica" e o seu uso é de que os escores para compreensão, em todos casos, foram maiores que aqueles obtidos para a percepção do uso.

Tabela 7 - Comparação das Medidas de Compreensão e Uso do Termo “Contabilidade Estratégica"

\begin{tabular}{l|c|c|c|c|c}
\multicolumn{1}{c|}{ Descrição } & Nova Zelândia * & Reino Unido * & Estados Unidos * & Sul e Sudeste Brasil ** & Professores \\
\hline Compreensão do Termo & 3,05 & 3,70 & 3,13 & 5,08 & 5,14 \\
\hline Uso do termo & 1,78 & 1,79 & 1,94 & 4,17 & 4,02
\end{tabular}

Fonte: * Guilding, Cravens e Tayles (2000) ** Grzeszezeszyn e Ferreira (2004)

Tabela 8 - Comparação das Medidas de Mérito das Práticas de Custeio e Precificação Estratégica

\begin{tabular}{l|c|c|c|c|c}
\multicolumn{1}{c|}{ Descrição } & Nova Zelândia * & Reino Unido * & Estados Unidos * & Sul e Sudeste Brasil ** & Professores \\
\hline Custeio de Atributos & 3,65 & 3,13 & 3,50 & 4,42 & 5,14 \\
\hline Custeio do Ciclo de Vida & 3,38 & 3,58 & 3,76 & 4,83 & 5,40 \\
\hline Custeio da Qualidade & 4,65 & 3,98 & 4,10 & 5,42 & 5,37 \\
\hline Custeio Estratégico & 4,86 & 4,98 & 4,93 & 5,58 & 5,14 \\
\hline Custeio Meta & 3,83 & 3,40 & 4,35 & 5,67 & 5,56 \\
\hline $\begin{array}{l}\text { Custeio de Cadeia } \\
\text { de Valor }\end{array}$ & 4,37 & 3,96 & 4,35 & 5,50 & 5,79 \\
\hline Precificação Estratégica & 5,32 & 5,38 & 5,62 & 5,67 & 5,47
\end{tabular}

Fonte: * Guilding, Cravens e Tayles (2000) ** Grzeszezeszyn e Ferreira (2004)

Tabela 9 - Comparação das Medidas de Mérito das Práticas de Análises dos Competidores

\begin{tabular}{l|c|c|c|c|c}
\multicolumn{1}{c|}{ Descrição } & Nova Zelândia * & Reino Unido * & Estados Unidos * & Sul e Sudeste Brasil ** & Professores \\
$\begin{array}{l}\text { Avaliação do Custo dos } \\
\text { Competidores }\end{array}$ & 5,16 & 5,49 & 5,26 & 5,17 & 5,67 \\
\hline $\begin{array}{l}\text { Monitoramento da } \\
\text { Posição Competitiva }\end{array}$ & 5,69 & 5,85 & 5,70 & 6,00 & 5,86 \\
\hline $\begin{array}{l}\text { Avaliação das Demons- } \\
\text { trações Financeiras dos } \\
\text { Competidores }\end{array}$ & 5,05 & 5,72 & 5,36 & 5,58 & 4,86
\end{tabular}


Tabela 10 Comparação das Medidas de Mérito das Práticas de Análise e Monitoramento da Marca

\begin{tabular}{l|c|c|c|c|c}
\multicolumn{1}{c|}{$\begin{array}{c}\text { Descrição } \\
\begin{array}{l}\text { Avaliação e Monitora- } \\
\text { mento da Marca }\end{array}\end{array}$} & 3,28 & 3,21 & 3,32 & 3,67 & Professores \\
\hline $\begin{array}{l}\text { Orçamento do Valor } \\
\text { da Marca }\end{array}$ & 3,42 & 3,42 & 3,45 & 3,75 & 4,14 \\
\hline
\end{tabular}

Fonte: * Guilding, Cravens e Tayles (2000) ** Grzeszezeszyn e Ferreira (2004)

Na abordagem internacional, as marcações médias para a compreensão ficaram abaixo do ponto de inflexão e variaram entre 3,05 a 3,70 de média, com uso menos intenso, cujas médias ficaram entre 1,78 a 1,94. As inferências de Guilding, Cravens e Tayles recaem na sugestão de que a definição de Contabilidade Estratégica ainda está imperfeita e/ou é imprópria, reforçando a alegação de Tomkins e Carr (1996) nesse sentido, citada na pesquisa. Na abordagem brasileira, as inferências foram na direção de que ainda existe confusão conceitual entre a Contabilidade Estratégica e a Contabilidade Gerencial tradicional.

Em relação às práticas de Contabilidade Estratégica, o "monitoramento da posição dos competidores" (Tabela 9) foi a que obteve as maiores médias em todos os levantamentos realizados, indicando ser aquela mais capaz em criar e manter vantagens competitivas, tanto na percepção dos controllers quanto dos docentes.

No agrupamento das práticas de custeio e precificação estratégica (Tabela 8), observa-se que, na percepção dos controllers (colunas 2 a 5), as práticas "precificação estratégica" e "custeio estratégico" foram as mais pontuadas, respectivamente, ao passo que para os docentes o "custeio estratégico" foi uma das menos pontuadas.

Como se relatou anteriormente, tal fato pode estar relacionado ao entendimento do conceito utilizado. Observe-se, ainda, que algumas práticas obtiveram pontuação abaixo do escore médio, sugerindo que ainda não são amplamente usadas.

Por fim, no agrupamento das práticas de análise e monitoramento da marca (Tabela 10), a prática de "orçamento do valor da marca” foi a mais pontuada, em média, pelos controllers, mas os resultados apontam valores abaixo do ponto médio. De acordo com a percepção dos docentes, a "avaliação e monitoramento da marca" foi a prática que obteve maior pontuação.

$A$ intuição inicial de que os professores têm melhor percepção que os controllers quanto ao mérito e à utilidade de práticas de Contabilidade Estratégica, baseado unicamente na estatística descritiva acima, foram evidenciadas, onde, de modo geral, os escores dos docentes foram maiores quando comparados com os escores dos controllers.

Para corroborar efetivamente essa intuição, ou refutá-la estatisticamente, pelo menos em relação à pesquisa de Grzeszezeszyn e Ferreira (2004), procedeu-se ao teste não-paramétrico de Mann-Whitney, cujo objetivo é testar as seguintes hipóteses:

$\mathrm{H}_{0}=$ não há diferença entre as percepções dos professores e controllers;

$\mathrm{H}_{1}=$ há diferença entre as percepções dos professores e controllers.

Na Tabela $11 \bullet$, constam o número de postos (coluna "N") de cada variável e para cada grupo analisado (professores e controllers), a média dos postos (coluna "Mean Rank") e a soma dos postos (coluna "Sum of Ranks") de cada grupo para as variáveis testadas, informações necessárias para elaboração do teste de Mann-Whitney, o qual aparecem na Tabela 120 .

Considerando os resultados apresentados na Tabela 12, pode-se dizer que para todas as variáveis estudadas, a hipótese nula $\left(\mathrm{H}_{0}\right)$ não pode ser rejeitada, ou seja, não existem diferenças significativas entre as percepções dos professores e dos controllers estudados por Grzeszezeszyn e Ferreira (2004).

Essas conclusões partem da análise do índice de Asymp. Sig. (2-tailed) na Tabela 12, na qual os sigs calculados para cada variável são superiores ao alfa de significância determinado para o teste $(\alpha=0,10)$, mostrando que as médias, ao nível de certeza de $90 \%$, são iguais.

O valor Z, mostrado nos testes, representa a magnitude da diferença nas médias dos grupos. Como os valores de $Z$ de cada variável ficaram dentro do intervalo do valor aceitável $(-1,64$ a $+1,64)$, conclui-se que as diferenças entre as médias dos dois grupos não são significativas estatisticamente.

Com isso, não se pode declarar categoricamente que as percepções dos docentes quanto ao mérito e à utilidade de práticas de Contabilidade Estratégica são melhores do que as dos controllers.

Contudo, fica claro o hiato que sempre existiu entre a teoria e o uso prático de certos conceitos. Isso é corroborado por Dixon (1998) em pesquisa empírica que visou compreender como uma organização poderia implantar e fazer uso prático do conceito de Contabilidade Estratégica. $\mathrm{O}$ resultado da pesquisa indicou que a Contabilidade Estratégica, como um conceito, é aceitável, mas que existem limitações práticas em sua aplicabilidade, tendo em vista o custo/benefício do processo (principalmente em relação à obtenção de dados externos). 
Tabela 11 Ranks do Teste de Mann-Whitney

\begin{tabular}{|c|c|c|c|c|c|c|c|c|c|}
\hline Ranks & GRUPOS & $\mathbf{N}$ & $\begin{array}{l}\text { Mean } \\
\text { Rank }\end{array}$ & $\begin{array}{l}\text { Sum of } \\
\text { Ranks }\end{array}$ & Ranks & GRUPOS & $\mathbf{N}$ & $\begin{array}{l}\text { Mean } \\
\text { Rank }\end{array}$ & $\begin{array}{c}\text { Sum of } \\
\text { Ranks }\end{array}$ \\
\hline Compreensão & Professores & 43,00 & 31,48 & 1353,50 & Custeio Cadeia & Professores & 43,00 & 31,94 & 1373,50 \\
\hline do Termo & $\begin{array}{l}\text { Controllers } \\
\text { Total }\end{array}$ & $\begin{array}{l}19,00 \\
62,00\end{array}$ & 31,55 & 599,50 & de Valor & $\begin{array}{l}\text { Controllers } \\
\text { Total }\end{array}$ & $\begin{array}{l}19,00 \\
62,00\end{array}$ & 30,50 & 579,50 \\
\hline Uso do Termo & $\begin{array}{l}\text { Professores } \\
\text { Controllers } \\
\text { Total }\end{array}$ & $\begin{array}{l}43,00 \\
19,00 \\
62,00\end{array}$ & $\begin{array}{l}31,08 \\
32,45\end{array}$ & $\begin{array}{r}1336,50 \\
616,50\end{array}$ & $\begin{array}{l}\text { Precificação } \\
\text { Estratégica }\end{array}$ & $\begin{array}{l}\text { Professores } \\
\text { Controllers } \\
\text { Total }\end{array}$ & $\begin{array}{l}43,00 \\
19,00 \\
62,00\end{array}$ & $\begin{array}{l}30,87 \\
32,92\end{array}$ & $\begin{array}{r}1327,50 \\
625,50\end{array}$ \\
\hline $\begin{array}{l}\text { Custeio de } \\
\text { Atributos }\end{array}$ & $\begin{array}{l}\text { Professores } \\
\text { Controllers } \\
\text { Total } \\
\end{array}$ & $\begin{array}{l}43,00 \\
19,00 \\
62,00 \\
\end{array}$ & $\begin{array}{l}32,36 \\
29,55\end{array}$ & $\begin{array}{r}1391,50 \\
561,50\end{array}$ & $\begin{array}{l}\text { Custos dos } \\
\text { Competidores }\end{array}$ & $\begin{array}{l}\text { Professores } \\
\text { Controllers } \\
\text { Total } \\
\end{array}$ & $\begin{array}{l}43,00 \\
19,00 \\
62,00 \\
\end{array}$ & $\begin{array}{l}30,55 \\
33,66\end{array}$ & $\begin{array}{r}1313,50 \\
639,50\end{array}$ \\
\hline $\begin{array}{l}\text { Custeio } \\
\text { Ciclo de Vida }\end{array}$ & $\begin{array}{l}\text { Professores } \\
\text { Controllers } \\
\text { Total } \\
\end{array}$ & $\begin{array}{l}43,00 \\
19,00 \\
62,00 \\
\end{array}$ & $\begin{array}{l}32,03 \\
30,29\end{array}$ & $\begin{array}{r}1377,50 \\
575,50\end{array}$ & $\begin{array}{l}\text { Posição } \\
\text { Competitiva }\end{array}$ & $\begin{array}{l}\text { Professores } \\
\text { Controllers } \\
\text { Total }\end{array}$ & $\begin{array}{l}43,00 \\
19,00 \\
62,00 \\
\end{array}$ & $\begin{array}{l}30,47 \\
33,84\end{array}$ & $\begin{array}{r}1310,00 \\
643,00\end{array}$ \\
\hline $\begin{array}{l}\text { Custeio da } \\
\text { Qualidade }\end{array}$ & $\begin{array}{l}\text { Professores } \\
\text { Controllers } \\
\text { Total }\end{array}$ & $\begin{array}{l}43,00 \\
19,00 \\
62,00 \\
\end{array}$ & $\begin{array}{l}30,92 \\
32,82\end{array}$ & $\begin{array}{r}1329,50 \\
623,50\end{array}$ & $\begin{array}{l}\text { Análise } \\
\text { Demonstrações } \\
\text { Financeiras }\end{array}$ & $\begin{array}{l}\text { Professores } \\
\text { Controllers } \\
\text { Total }\end{array}$ & $\begin{array}{l}43,00 \\
19,00 \\
62,00 \\
\end{array}$ & $\begin{array}{l}29,27 \\
36,55\end{array}$ & $\begin{array}{r}1258,50 \\
694,50\end{array}$ \\
\hline $\begin{array}{l}\text { Custeio } \\
\text { Estratégico }\end{array}$ & $\begin{array}{l}\text { Professores } \\
\text { Controllers } \\
\text { Total }\end{array}$ & $\begin{array}{l}43,00 \\
19,00 \\
62,00 \\
\end{array}$ & $\begin{array}{l}29,92 \\
35,08\end{array}$ & $\begin{array}{r}1286,50 \\
666,50\end{array}$ & $\begin{array}{l}\text { Avaliação } \\
\text { da Marca }\end{array}$ & $\begin{array}{l}\text { Professores } \\
\text { Controllers } \\
\text { Total }\end{array}$ & $\begin{array}{l}43,00 \\
19,00 \\
62,00 \\
\end{array}$ & $\begin{array}{l}33,57 \\
26,82\end{array}$ & $\begin{array}{r}1443,50 \\
509,50\end{array}$ \\
\hline $\begin{array}{l}\text { Custeio } \\
\text { Meta }\end{array}$ & $\begin{array}{l}\text { Professores } \\
\text { Controllers } \\
\text { Total }\end{array}$ & $\begin{array}{l}43,00 \\
19,00 \\
62,00\end{array}$ & $\begin{array}{l}29,93 \\
35,05\end{array}$ & $\begin{array}{r}1287,00 \\
666,00\end{array}$ & $\begin{array}{l}\text { Orçamento } \\
\text { Marca }\end{array}$ & $\begin{array}{l}\text { Professores } \\
\text { Controllers } \\
\text { Total }\end{array}$ & $\begin{array}{l}43,00 \\
19,00 \\
62,00\end{array}$ & $\begin{array}{l}33,60 \\
26,74\end{array}$ & $\begin{array}{r}1445,00 \\
508,00\end{array}$ \\
\hline
\end{tabular}

Fonte: Elaborada pelos autores, com adaptação do SPSS

Tabela 12 Estatística Teste de Mann-Whitney

\begin{tabular}{|c|c|c|c|c|c|c|c|}
\hline Test Statistics(a) & $\begin{array}{c}\text { Compreensão } \\
\text { do Termo }\end{array}$ & $\begin{array}{l}\text { Uso do } \\
\text { Termo }\end{array}$ & $\begin{array}{l}\text { Custeio de } \\
\text { Atributos }\end{array}$ & $\begin{array}{c}\text { Custeio Ciclo } \\
\text { de Vida }\end{array}$ & $\begin{array}{l}\text { Custeio da } \\
\text { Qualidade }\end{array}$ & $\begin{array}{c}\text { Custeio } \\
\text { Estratégico }\end{array}$ & $\begin{array}{l}\text { Custeio } \\
\text { Meta }\end{array}$ \\
\hline Mann-Whitney U & 407,50 & 390,50 & 371,50 & 385,50 & 383,50 & 340,50 & 341,00 \\
\hline Wilcoxon W & 1353,50 & 1336,50 & 561,50 & 575,50 & 1329,50 & 1286,50 & 1287,00 \\
\hline Z & $-0,016$ & $-0,279$ & $-0,576$ & $-0,360$ & $-0,392$ & $-1,071$ & $-1,070$ \\
\hline Asymp. Sig. (2-tailed) & 0,987 & 0,781 & 0,565 & 0,719 & 0,695 & 0,284 & 0,285 \\
\hline Test Statistics(a) & $\begin{array}{l}\text { Custeio } \\
\text { Cadeia de } \\
\text { Valor }\end{array}$ & $\begin{array}{l}\text { Precificação } \\
\text { Estratégica }\end{array}$ & $\begin{array}{c}\text { Custos dos } \\
\text { Competidores }\end{array}$ & $\begin{array}{c}\text { Posição } \\
\text { Competitiva }\end{array}$ & $\begin{array}{c}\text { Análise } \\
\text { Demonstrações } \\
\text { Financeiras }\end{array}$ & $\begin{array}{l}\text { Avaliação } \\
\text { da Marca }\end{array}$ & $\begin{array}{c}\text { Orçamento } \\
\text { Marca }\end{array}$ \\
\hline Mann-Whitney U & 389,50 & 381,50 & 367,50 & 364,00 & 312,50 & 319,50 & 318,00 \\
\hline Wilcoxon W & 579,50 & 1327,50 & 1313,50 & 1310,00 & 1258,50 & 509,50 & 508,00 \\
\hline Z & $-0,301$ & $-0,427$ & $-0,650$ & $-0,714$ & $-1,499$ & $-1,384$ & $-1,418$ \\
\hline Asymp. Sig. (2-tailed) & 0,763 & 0,669 & 0,516 & 0,475 & 0,134 & 0,166 & 0,156 \\
\hline
\end{tabular}

(a) Grouping Variable: grupos

Fonte: Elaborada pelos autores, com adaptação do SPSS

\section{CONSIDERAÇÕES FINAIS}

A afirmação de Goldenberg (1994) e Coad (1996) de que a Contabilidade Estratégica é um ramo da Contabilidade em expansão, cujos limites ainda precisam ser claramente definidos, foi captada no levantamento realizado junto aos docentes dos programas de pós-graduação em Contabilidade no Brasil.

Apesar de a maioria dos escores obtidos terem se situado do ponto médio para cima no grau de concordância, a dispersão das pontuações mostram que não existe homogeneidade quanto ao significado da Contabilidade Estratégica e de sua aplicação, mesmo passados mais de dez anos das primeiras pesquisas sobre $o$ assunto.

Fica claro, também, na percepção dos docentes, que a maioria das práticas de Contabilidade Estratégica pesquisada contribuem de certa maneira na identificação de estratégias que criam vantagens competitivas para a empresa ou 
adicionam valor sobre seus competidores, proporcionando benefícios para a empresa sobre decisões de longo prazo.

Deve-se levar em conta, nesse contexto, a relação custo/benefício da utilização efetiva de certas práticas (custeio dos atributos, avaliação e monitoramento da posição dos competidores, custeio da cadeia de valor etc.) em função da dificuldade para obtenção de dados que conduzam a informações dos competidores com grau de subjetividade aceitável, tendo em vista que muitos deles não estão facilmente disponíveis ou, ainda, a dificuldade de mensuração da percepção de valor dos agentes envolvidos no processo.

Destaque-se o papel a ser desempenhado pelo contador ou controller apontado por Ferreira (1992), Nossa e Holanda (1998) e Dixon (1998), o qual seria o maestro na condução da Contabilidade Estratégica para atingir seus objetivos.

Nos levantamentos realizados, constatou-se que a utilização de algumas práticas de Contabilidade Estratégica ainda são pouco expressivas (principalmente como evidenciado em Guilding, Cravens e Tayles, 2000), indicando a necessidade cada vez maior de contadores dinâmicos, com atitudes proativas, que se preocupam em abrir as portas e ir para fora da empresa na busca de informações para o ambiente interno de modo a dar condições à empresa em criar e manter vantagens competitivas no curto, médio e longo prazos.

Por fim, destaque-se que as práticas pesquisadas não espelham, de maneira alguma, o universo das práticas de Contabilidade Estratégica, pois, como se constatou, a própria Contabilidade Estratégica ainda está se sedimentando, indicando que ainda existe espaço para o aperfeiçoamento teórico da Contabilidade Estratégica, com vista à consolidação do seu significado e de como ela pode se desenvolver, adequadamente, no ambiente organizacional, sendo um campo fértil para futuras investigações.

Desse modo, outras pesquisas empíricas são válidas no sentido de suscitar novas hipóteses e problemas quanto à aplicabilidade da Contabilidade Estratégica mediante pesquisas do tipo estudo de caso direcionadas a setores econômicos específicos para corroborar ou não as constatações a respeito do uso das práticas de Contabilidade Estratégica.

\section{Referências Bibliográficas}

COAD, Alan. Smart work and hard work: explicating a learning orientation in strategic management accounting. Management Accounting Research, n. 7, p. 387-408, 1996.

DIXON, Rob. Accounting for strategic management: a practical application. Long Range Planning, v. 31, n. 2, p. 272-279, 1998.

FERREIRA, Aracéli Cristina de Sousa. A contabilidade estratégica e o mundo dos negócios. Boletim do Ibracon, ano XV, n. 171, ago., 1992, p. 2-5.

FERREIRA, Aracéli Cristina de Sousa; PORTUGAL, Guilherme Teixeira; NIGRI, Hélio Sergio. Estratégias para as Ciências Contábeis do século XXI - Um estudo do Passado para Proposições de Futuro. In: CONGRESO DEL INSTITUTO INTERNACIONAL DE COSTOS, 7., 2001, Leon, Espanha. Anais... Leon, 2001.

GIL, Antonio Carlos. Métodos e técnicas de pesquisa social. 5. ed. São Paulo: Atlas, 1999.

GOLDENBERG, Marta da Conceição Louro. Contabilidade estratégica: o papel do controller no processo de planejamento estratégico. 1994. Dissertação (Mestrado em Controladoria e Contabilidade). Faculdade de Economia, Administração e Contabilidade. Universidade de São Paulo, SP.

GRZESZEZESZYN, Gilberto. Contabilidade gerencial estratégica no Sul e Sudeste do Brasil: uma abordagem do estudo "An international comparison of strategic management accounting practices". 2004. Dissertação (Mestrado em Ciências Contábeis). FACC/UFRJ, Rio de Janeiro, RJ.

; FERREIRA, Aracéli Cristina de Sousa. Práticas de contabilidade gerencial estratégica no Sul e Sudeste do Brasil: uma abordagem do estudo "An international comparison of strategic management accounting practices". In: ENCONTRO DA ANPAD - EnANPAD, 28., 2004, Curitiba. Anais ... Curitiba: ANPAD, 2004. CD ROM.

GUILDING, Chris; CRAVENS, Karen S.; TAYLES, Mike. An international comparison of strategic management accounting practices. Management Accounting Research, n. 11, p. 113-135, 2000.

HENDRIKSEN, Eldon S.; VAN BREDA, Michael F.. Teoria da contabilidade. São Paulo: Atlas, 1999.

IUDÍCIBUS, Sérgio de. Contabilidade gerencial: novos paradigmas. In: CONGRESSO BRASILEIRO DE GESTÃO ESTRATÉGICA DE CUSTOS, 1., 1994, São Leopoldo/RS. Anais... São Leopoldo: ABC, 1994.

; MARTINS, Eliseu; CARVALHO, L. Nelson. Contabilidade: aspectos relevantes da epopéia de sua evolução. Revista Contabilidade \& Finanças. n. 38, p. 7-19, maio/ago., 2005.

JOHNSON, H. Thomas; KAPLAN, Robert S.. Contabilidade gerencial. Rio de Janeiro: Campus, 1993.

LOPES, Alexsandro Broedel; MARTINS, Eliseu. Teoria da contabilidade: uma nova abordagem. São Paulo: Atlas, 2005.

LORD, Beverly R. Strategic management accounting: the emperor's new clothes? Management Accounting Research, n. 7, p. 347-366, 1996.

MAROCO, João. Análise estatística com utilização do SPSS. 2. ed. Lisboa: Silabo, 2003.

MARCONI, Marina de Andrade; LAKATOS, Eva Maria. Técnicas de pesquisa. 4. ed. São Paulo: Atlas, 1999. 
MARTINS, Gilberto de Andrade. Estatística geral e aplicada. 3. ed. São Paulo: Atlas, 2006.

NOSSA, Valcemiro; HOLANDA, Victor Branco de. A contabilidade estratégica e os sistemas de informações como suporte às decisões. In: CONGRESSO BRASILEIRO DE CUSTOS, 5., Fortaleza. Anais... Fortaleza: UFC, 1998.

SHANK, John K.; GOVINDARAJAN, Vijay. A revolução dos custos. 8. ed. Rio de Janeiro: Campus, 1997.

SIMMONDS, Kenneth. Strategic management accounting. Management Accounting, v. 59, n. 4, p. 26-29. Apr. 1981.

STAINER, Allan. Productivity and strategic management accounting. International Journal of Technology Management, v. 13, n. 1, p. $57-67,1997$.

TOMKINS, Cyril; CARR, Chris. Reflections on the papers in this issue and a commentary on the state of Strategic Management Accounting. Management Accounting Research, v. 7, n. 2, p. 271-280, jun. 1996.

\section{NOTA - Endereço dos autores}

Universidade Federal do Rio de Janeiro

Av. Pedro Calmon, 500 - Cidade Universitária

Rio de Janeiro - RJ

21941-901 